\section{Tetralogy of Fallot: The Oldest Reported Survivor of Brock's Procedure}

\author{
Rama Bindu Manchikalapudi and Bruce D. Klugherz: \\ Clin Cardiol 2008;31:556-558
}

\section{To the Editor:}

The Short Communication of Manchikalapudi and Klugherz regarding the oldest reported survivor of Brock's procedure for tetralogy of Fallot is of great interest. ${ }^{1}$ What is likely, however, is that there was an incomplete resection of the subvalvar and valvar right ventricular outflow tract obstruction at the time of the surgery. In the presence of a large ventricular septal defect (typically present with this lesion and shown in figure 2 of their report), the individual would have developed a significant left to right shunt, resulting in pulmonary artery hypertension, leading to pulmonary vascular disease incompatible with survival to 79 years.

The oxygen saturation and gradient across the pulmonic valve were not provided in the communication. Had they been presented, I expect we would have seen relatively low saturation and flow acceleration across the right ventricular outflow tract (accounting for the right ventricular hypertrophy seen, as well as the prominent murmur noted). Residual outflow tract obstruction would have prevented pulmonary over-circulation, allowing for a more balanced circulation and greater longevity. This seems to be a case in which less surgical resection is better for the patient.

Jeffery H. Kern, MD, FACC, FAPP

Department of Pediatric Cardiology

New York Presbyterian Hospital New York, New York

\section{Reference}

1. Manchikalapudi RB, Klugherz BD. Tetralogy of Fallot: the oldest reported survivor of Brock's procedure. Clin Cardiol.. 2008;31(11): 556-558.

\section{Reply:}

We appreciate the letter submitted by Dr. Jeffrey Kern regarding our previously published Short Communication.

Dr. Kern's comments highlight the insight of Dr. R.C. Brock when he set out to perform pulmonary valvulotomy without promoting pulmonary over-circulation in a high risk group of patients with pulmonary stenosis. Dr. Brock performed his valvulotomies based on preoperative clinical assessment and direct cardiac examination intraoperatively, without a quantitative understanding of the patients' hemodynamics. In large part, his decision to proceed with valvulotomy was driven by the character and location of the pulmonic thrill immediately following pericardiotomy.
In his beating-heart operation, Dr. Brock utilized a curved valvulotome and dilating forceps to alleviate the outflow obstruction via a right ventricular approach; obligately this resulted in incomplete relief of the outflow obstruction, as Dr. Kern postulates was the situation in our patient. Indeed, our patient's last echocardiogram, before his unfortunately fatal pelvic fracture, demonstrated a peak trans-pulmonic valve gradient of $100 \mathrm{~mm} \mathrm{Hg}$ and a mean trans-pulmonic valve gradient of $46 \mathrm{~mm} \mathrm{Hg}$. Assumedly of lower magnitude than his preoperative gradient, no doubt this residual gradient was sufficiently large to prevent pulmonary overcirculation, thereby contributing to our patient's longevity.

Rama Bindu Manchikalapudi, MD Department of Internal Medicine Abington Memorial Hospital Abington, Pennsylvania

Bruce D. Klugerz, MD Department of Cardiology Abington Memorial Hospital Abington, Pennsylvania

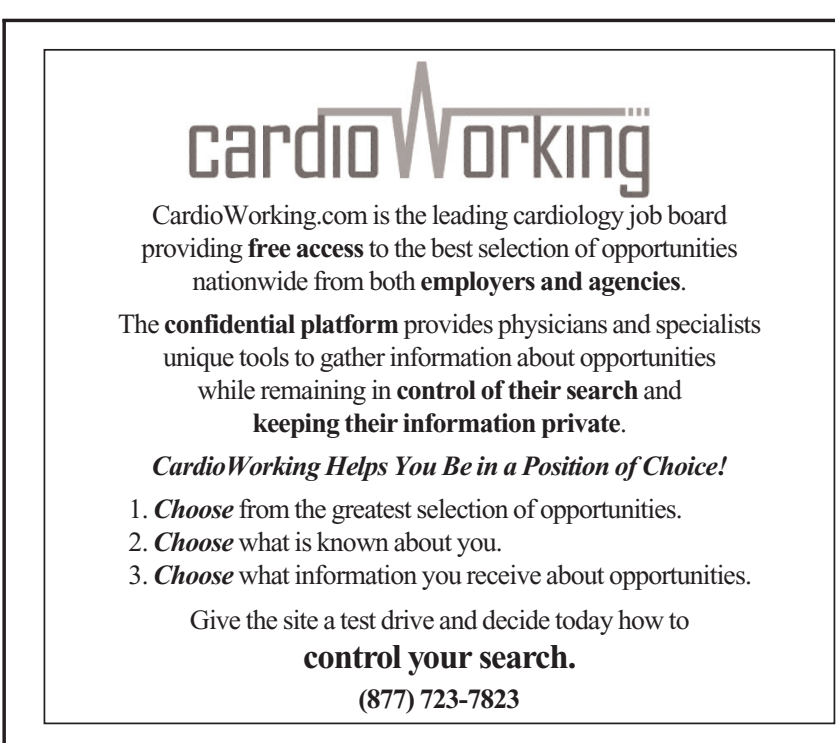

\section{INDEX TO ADVERTISERS}

Atacand $350, \mathrm{C} 3, \mathrm{C} 4$

Plavix $\mathrm{C} 2-\mathrm{A} 1, \mathrm{~A} 2$

Ranexa 299 A-D

Tracleer 307, $307 \mathrm{~A}-\mathrm{B}$

Classified Advertising 349

This index is provided as a service. Every effort to achieve accuracy is made. Publisher is not responsible for errors or omissions. 